\title{
방범용 $\mathrm{CCTV}$ 를 위한 배회행위 탐지 솔루션 \\ 강주형 ${ }^{\dagger}$, 곽수영 $^{+\dagger}$
}

\section{요 약}

본 논문에서는 지능형 감시 시스템을 위해 공간적 확률 분포와 방향 서술자를 이용하여 다양한 배회행위를 검출하는 방법을 제안한다. 적응적 배경 모델링 기법을 이용하여 움직이는 객체를 검출하고, 검출된 객체로부 터 움직임의 정보를 추출한다. 추출된 객체의 움직임 정보는 이동 궤적과 방향에 대해 특징벡터를 생성한다. 생성된 특징벡터는 $\mathrm{k}-$ Nearest Neighbor를 통해 최종적으로 배회행위를 검출하게 된다. 제안한 방법을 실내 외 다양한 환경에서 테스트하여 배회 행위를 검출하는 결과를 나타내었으며 이는 실시간으로 검출되는 것을 확인하였다.

\section{Loitering Detection Solution for CCTV Security System}

\author{
Joohyung Kang ${ }^{\dagger}$, Sooyeong $\mathrm{Kwak}^{+\dagger}$
}

\section{ABSTRACT}

In this paper, we propose a loitering detection using trajectory probability distribution and local direction descriptor for intelligent surveillance system. We use a background modeling method for detecting moving object and extract the motion features from each moving object for making feature vectors. After that, we detect the loitering behavior person using $\mathrm{K}$-Nearest Neighbor classifier. We test the proposed method in real world environment and it can achieve real time and robust detection results.

Key words: intelligent surveillance system(지능형 감시 시스템), loitering detection(배회 행위 탐지), trajectory analysis(궤적 분석)

\section{1. 서 론}

최근 몇 년 사이 국제 테러 등으로 인해 보안에 대한 인식이 강화되면서 영상보안 솔루션 기술이 지 속적으로 발전하고 있다. 또한, 최근 일어난 각종 강 력범죄 사건 사고 해결에 $\mathrm{CCTV}$ 가 결정적인 역할을 하면서 공공 부문과 민간 보안 부문으로 수요가 확대 되고 있다. 하지만, 해상도가 낮아 영상정보를 알아 볼 수 없거나 야간이나 눈, 비, 안개 등 외부환경의 변화에 매우 취약해 범죄 상황 발생 시의 효율적으로

※ 교신저자(Corresponding Author): 곽수영, 주소 : 대전 광역시 유성구 덕명동 한밭대학교 N5동 310호(305-719), 전화 : 042) 821-1167, FAX : 042) 821-1164, E-mail : sykwak@hanbat.ac.kr 접수일 : 2013년 7월 17일, 수정일 : 2013년 11월 4일 완료일 : 2013년 11월 22일
대처하기 어려운 경우가 많다. 또한, 설령 $\mathrm{CCTV}$ 에 문제가 없더라도 어떠한 사고가 발생하기 전의 예방 보다는 주로 범인 검거와 같은 사후처리에 주로 활용 되는 것이 현실이다. 24 시간 입력되는 방대한 감시 영상을 효율적으로 처리해야 하지만 사람이 지속적 으로 감시하는 기존의 방식으로는 한계가 있기 때문 이다. 최근 이러한 문제를 해결하기 위해 이상행위라 고 의심이 되는 행동 패턴이 발생하면 자동으로 알람 을 알려주어 능동적으로 대처할 수 있는 지능형 영상 분석 솔루션이 요구되고 있다.

\footnotetext{
${ }^{+}$학생회원, 한밭대학교 제어계측공학과

(E-mail : kangjh@hanbat.ac.kr)

${ }^{++}$정회원, 한밭대학교 전자·제어공학과

※ 본 연구는 한밭대학교 교내학술연구비 및 2013년도 정 부(교육과학기술부)의 재원으로 한국연구재단의 지원을 받아 수행된 기초연구사업임(NRF-2011-0007406)
} 
방범용으로 사용되는 지능형 영상분석 솔루션은 영상 내 이상행위를 하는 사람이 감지되면 보안 감시 자에게 알림을 발생함으로써 사건 사고를 미연에 방 지하는 것을 목적으로 하고 있다. 이는 최소 인력으 로 보안 효율을 높일 수 있으며, 유지관리 비용까지 절감하는 효과를 창출하게 되었다. 계획된 범죄는 범 죄자의 행동에 일정한 패턴이 있기 때문에 이러한 패턴을 사전에 파악 하고, 동일한 행동 패턴이 감지 되면 즉각 대응함으로써 범죄를 사전에 대응할 수 있을 것이다. 방범용 감시시스템의 이상행위는 경계 구역 내 침입자 감지, 특정 구역에서의 배회자 및 도 주자 감지, 비 혼잡지역의 방치 물체 감지 등이 있다. 본 논문에서는 대부분의 범죄 발생 시 가장 먼저 보 이게 되는 배회 행위[1]를 검출하는 것에 초점을 맞 추었다.

많은 연구자들이 배회행위를 검출하기 위해 특정 영역에 장시간 반복적으로 머무르는 사람을 검출하 는 방법을 사용하였다. Lee[2] 등은 영상 내의 객체가 동일한 영역에 궤적이 반복적으로 발생할 때 배회 행위의 특성으로 간주하여 이를 검출하는 알고리즘 을 제안하였다. 이를 검출하기 위해 영상을 특정 크 기의 블록으로 나누어 이동 궤적을 관찰하는 블록기 반의 이동 객체를 분석하는 방법을 제안하였다. Huang[3]등은 외관모델을 이용한 베이지안(Bayesian) 추적기를 이용하여 움직이는 보행자라고 예측되는 객체를 추적한 뒤 영상 내 등장하는 보행자들의 방문 기록을 테이블로 구성한 LV(List of Visitors)을 통 해 배회행위를 하는 사람을 검출하는 알고리즘을 제 시하였다. Thi Thi $\operatorname{Zin}[4]$ 등은 전경과 배경을 분리하 여 얻어진 객체의 궤적정보를 토대로 외형 모델 특징 과 움직임 모델 특징을 추출하여 마르코프 랜덤워크 모델(Markov Random Walk Model)이용하여 배회 행위를 검출하는 방법을 제안하였다. 이러한 방법은 영상 내에서의 2 차원 궤적으로 분석하는 방법을 사 용한 반면 Park[5]는 움직이는 객체의 그림자 제거를 통해 정확하게 검출한 후 카메라 캘리브레이션 (calibration)을 이용하여 실세계 즉, 3 차원 궤적 분석 을 통해 배회행위를 검출하는 방법을 사용하였다. 이 러한 방법의 경우 특정영역 즉, 지역적 공간에 장시 간 머무르며 배회행위를 하는 사람 검출에는 유용하 지만 영상이 모든 영역을 배회하는 행위를 하는 사람 들을 파악하는데 어려움이 있다.
본 논문에서는 방법용 CCTV에 유용한 다양한 배 회 행위를 검출하는 방법을 제안한다. 2장에서는 제 안하는 시스템의 개요와 움직이는 객체를 검출하는 방법을 설명하고 3장에서는 움직임 정보를 기반으로 배회 행위 검출기법을 설명한다. 그리고 4 장에서는 본 방법론을 실제 영상에 적용한 실험 결과 및 분석 을 설명하고 마지막으로 5장에서 결론을 맺는다.

\section{2. 제안하는 배회 행위 검출 시스템}

감시 영상에서 배회하는 객체를 검출[6]하는 것은 다른 이상행위[7]와는 다르게 사건사고를 미연에 방 지할 수 있어 여러 이상행위 중에서도 중요한 이슈이 다. 배회행위의 사전적 의미는 "어슬렁거리며 이리 저리 돌아다니다."의 표현으로 의미 특성상 정확하 고 명확한 규칙과 규정을 내릴 수가 없다. 본 논문에 서는 통상적인 배회행위의 특성과 사전적 의미를 참 조하여 다음과 같이 2 가지의 배회행위규칙을 정의하 였다.

[정의 1] 배회자는 특정구역에서 반복적인 움직임 특성을 갖는다.

[정의 2] 배회자의 이동 동선은 규칙적이지 않으 며 목표지점이 불투명한 특성을 갖는다.

[정의 1]과 [정의 2]는 설명할 수 있는 모든 배회행 위의 내용을 함축적으로 정리한 것이다. 대부분의 배 회행위 검출 알고리즘의 경우 [정의 1]만 사용하여 검출하였지만 실질적으로 배회 행위는 [정의 2]의 특 성 또한 포함하고 있다. 본 논문에서는 두 가지 정의 를 모두 사용하여 다양한 배회 행위 검출이 가능한 알고리즘을 제안한다.

본 논문에서 제안하는 배회행위 검출기법의 흐름 도는 그림 1 과 같다. 먼저 배경 모델링 기법을 이용하 여 움직이는 객체를 검출하고, 검출된 객체로부터 움 직임의 정보를 추출하여 분석한다. 추출된 객체의 움 직임 정보는 이동 궤적과 방향의 두 특징정보를 생성 하는데 사용되고, 시스템은 두 특징정보에 대하여 시 간에 따른 변화를 분석하여 2차원의 특징벡터를 생 성한다. 생성된 특징벡터는 $\mathrm{k}$-Nearest Neighbor를 통해 최종적으로 배회행위를 검출하게 된다. 


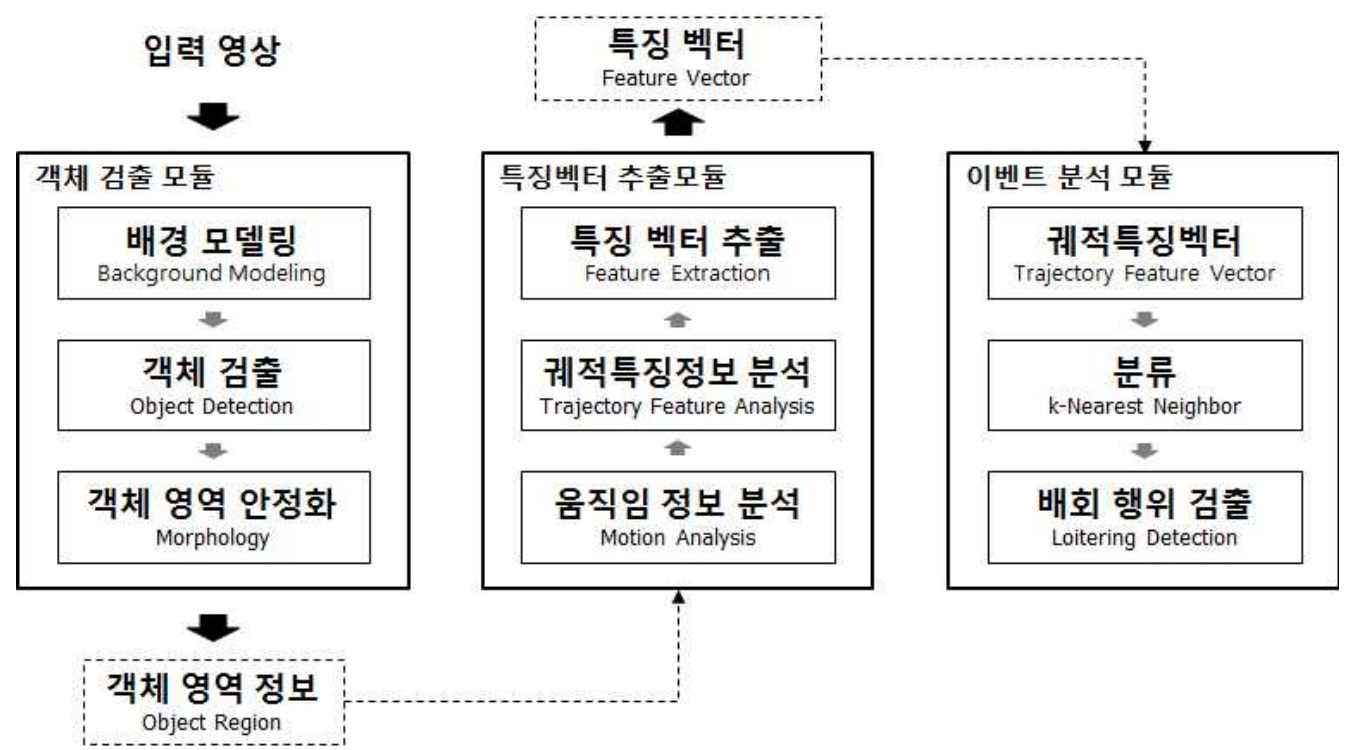

그림 1. 제안하는 배회행위 검출 흐름도

\section{3. 평균 배경 모델을 이용한 객체 검출}

본 논문에서는 움직이는 객체를 검출하기 위하여 고정카메라 환경에서 가장 많이 사용하는 배경모델 링 방법을 사용하였는데 여러 가지 배경모델링[810] 알고리즘 가운데 평균 배경 모델 방법을 적용하 였다. 이는 간단한 연산으로 이루어져 실시간 처리가 가능하다는 장점을 가지고 있지만, 이전 프레임의 정 보를 기억하기 위한 메모리의 낭비가 많고, 배경 영 상과 현재 프레임의 화소 명암 차이가 클 경우 평균 값이 너무 빨리 변하여 명확한 배경 및 전경 분리가 되지 않는다는 문제점이 존재한다. 본 논문에서는 보 다 효과적인 배경 모델링을 하기위해 화소단위 평균 학습법이 아닌 휘도 단위로 평균 배경 모델 방법을 적용하였다.

휘도단위 평균 배경 모델은 영상의 배경 부분을 일정시간 샘플링하여 화소들의 평균 휘도 값을 계산
한 결과 값을 배경 프레임으로 기준 영상을 생성한 다. 평균 영상에 수치적인 파라미터 값을 연산하여 상위 임계영상과 하위 임계영상을 생성하고, 시스템 은 두 기준영상과 입력영상의 차연산을 수행하여 객 체를 검출하게 된다. 이 때 시스템은 매 프레임마다 적응적으로 기준영상을 갱신함으로써 입력영상에 대한 조명변화와 이동객체의 배경화에 따른 문제를 강인하게 해결할 수 있다. 배경 학습을 통하여 검출 된 객체는 잡음과 불안정하게 추출된 영역을 보완하 기 위해 형태학 처리기법으로 모폴로지 연산을 수행 한다. 그림 2 는 평균 영상에 대한 두 기준 영상과 그 에 따른 객체검출결과를 나타내고 있다.

\section{4. 배회 행위 검출}

\section{1. 궤적 확률분포 생성}

단순히 시간에 따라 객체의 존재 여부에 의존하는

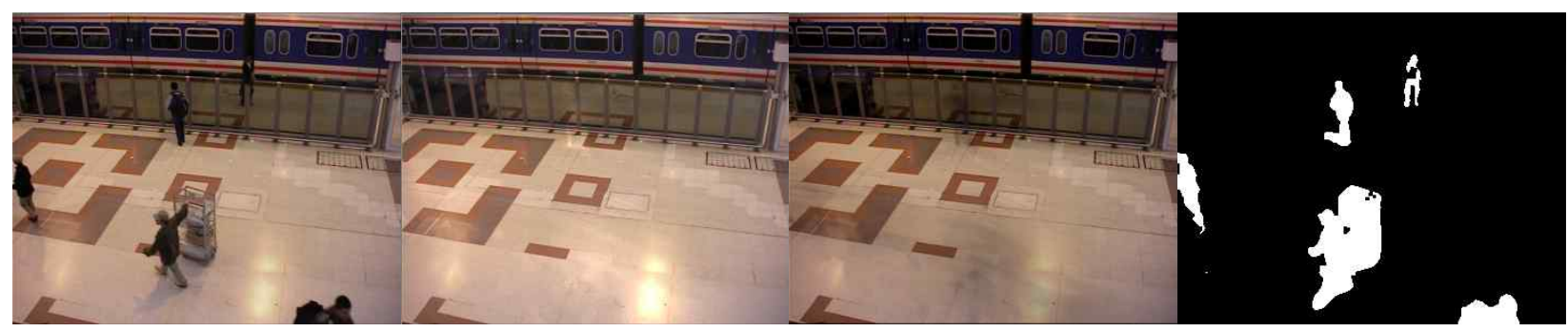

(a) 입력 영상

(b) 상위 임계영상

(c) 하위 임계영상

(d) 객체검출 결과

그림 2. 평균 배경모델 학습을 통한 객체검출 결과 
기존의 배회행위 검출기법과는 달리 본 절에서는 궤 적정보[11]의 시공간적인 확률분포를 이용하여 보다 직관적으로 배회행위를 검출하는 방법을 제안한다. 제안하는 방법은 먼저 이동궤적에 대한 패턴을 분석 하기 위하여 임의의 화소를 양자화(quantization)하 여 입력 영상에 대한 공간적 모델[12,13]을 생성한다. 일반적으로 이동궤적은 수식(1)과 같이 객체 영역의 무게중심을 원소로 갖는 집합체로 이루어져 있다. 수 식(1)의 $X\left(\overrightarrow{p_{j}^{t}}\right)$ 은 시간에 따른 검출된 이동객체의 영 역 무게중심을 나타내고 있다.

$$
\text { Trajectory }=\left\{X\left(p_{i}^{t-n}\right), X\left(p_{i}^{t-(n-1)}, X\left(p_{i}^{t-2}\right), \cdots, X\left(p_{i}^{t}\right)\right\}\right.
$$

이러한 궤적정보들은 영상공간에서 하나의 화소 로 표현할 수 있는데 이는 시간성과 연산측면에서 매우 비효율적인 결과를 도출하므로 임의의 화소를 프리스케일링(prescaling)하여 양자화 하였다. 이렇 게 생성된 공간적 모델에 궤적을 적용하여 시간에 따른 궤적을 재표현 하였고, 각각의 공간적 모델은 전체 시간으로 정규화하여 영상공간에 대한 궤적의 확률값으로 나타내었다. 시간 $\mathrm{t}$ 에 따른 공간적 모델 의 확률은 다음과 같이 정의된다.

$$
\begin{aligned}
& P_{\text {Traj }}\left(S_{i}\right)=N\left(\sum\left(X\left(\overrightarrow{p_{j}^{t}}\right) \in \overrightarrow{S_{i}}\right)\right) \\
& \overrightarrow{p_{j}^{t}}=\left(L t\left(x_{j}^{t}, y_{j}^{t}\right), R b\left(x_{j}^{t}, y_{j}^{t}\right)\right)
\end{aligned}
$$

위의 수식(2)에서 $\overrightarrow{S_{i}}$ 는 공간적 모델을 나타내며, $X\left(\overrightarrow{p_{j}^{t}}\right) \in \overrightarrow{S_{i}}$ 는 시간 $\mathrm{t}$ 에 따른 공간적 모델의 객체 무게 중심. 즉, 궤적을 의미한다. 함수 $N(\bullet)$ 은 공간적 모 델을 정규화 한다는 의미이고, 수식(3)의 $\overrightarrow{p_{j}^{t}}$ 는 검출 된 객체의 영역정보를 나타내고 있다.

궤적 확률분포를 통하여 특징정보를 추출하는 목 적은 공간상에서의 반복적인 움직임패턴을 파악하 는 것이다. 각각의 공간적 모델이 높은 확률값을 갖 는다는 의미는 이동객체의 움직임특성이 강하다는 것으로 해석할 수 있는데 본 논문에서는 낮은 확률값 을 감쇠시키면서 높은 확률값, 즉 특징성을 부각시키 는 과정으로 2 차원 가우시안 필터(gaussian filter) [14]를 사용하였다.

시스템은 매 프레임마다 공간적 확률모델을 객체 의 움직임 정보와 2차원 가우시안 필터를 통해 갱신 하며, 수식 (4)과 같이 $\mathrm{N}$ 차원의 궤적 확률벡터로 표 현할 수 있다. 그림 3 은 가우시안 필터링을 적용하여 궤적 확률벡터가 갱신된 모습을 보여주고 있다. 수식 (4)의 $G\left(P_{T r a j}\left(S_{n}\right)\right)$ 는 필터링을 거친 각각의 공간적 모델을 의미하며, $\overrightarrow{P_{T}}$ 는 갱신된 공간적 모델을 벡터 화 한 궤적 확률벡터이다. 그림 3-(a)의 그래프에서 파란색상의 분포는 낮은 확률값을 가지는 공간적 모 델, 붉은색상의 분포는 높은 확률값을 가지는 공간적 모델이다. 2 차원 가우시안 필터를 통해 각각의 공간
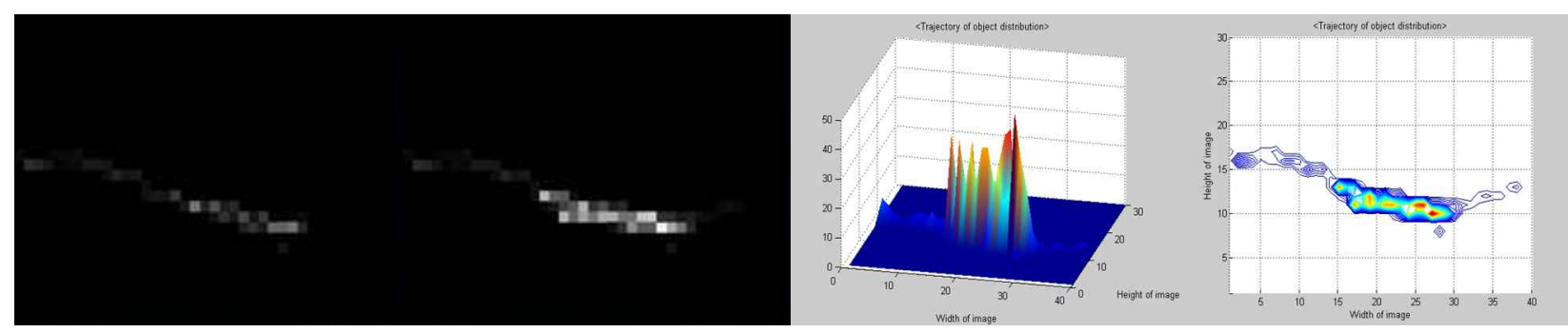

(a) 2 차원 가우시안 필터링 적용 전 공간적 모델
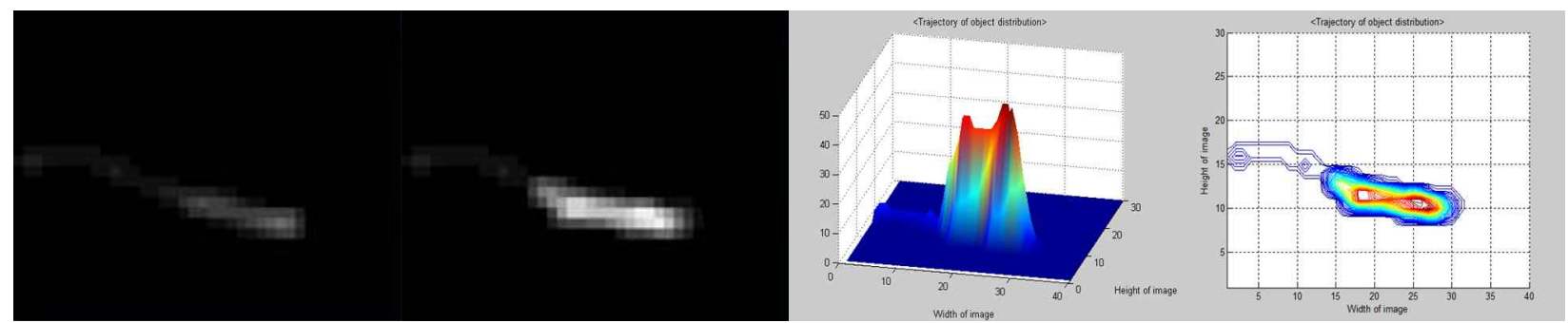

(b) 2차원 가우시안 필터링 적용 후 공간적 모델

그림 3. 필터링을 통한 안정적인 모델 갱신 


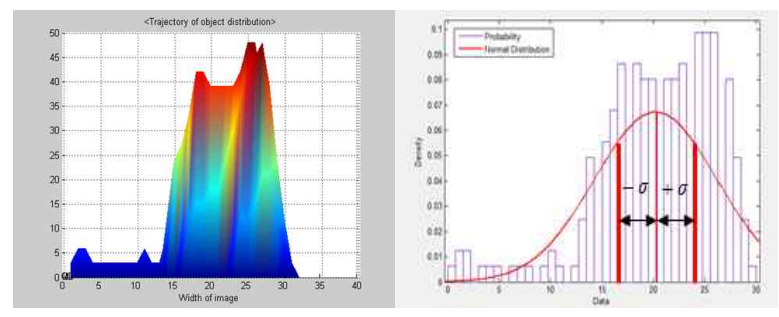

그림 4. 궤적 확률분포의 구간적분

적 모델에 가중치를 부여하여 그림 3-(b)의 그래프 와 같이 높은 확률값과 낮은 확률값의 경계를 확실하 게 나타내었다.

$\overrightarrow{P_{T}}=\left[G\left(P_{T r a j}\left(S_{1}\right)\right), G\left(P_{T r a j}\left(S_{2}\right)\right), \cdots, G\left(P_{T r a j}\left(S_{n}\right)\right)\right]$

필터링을 거쳐 안정적인 모델로 갱신된 확률벡터 는 궤적의 분포를 추정하기 위하여 누적 히스토그램 을 생성하고 그에 따른 통계적 파라미터를 추출하게 된다. 앞서 제시한 [정의 1]의 배회행위 특성을 파악 해 보면 움직임에 대한 공간적인 분포는 반복적인 움직임의 구간에서 높게 형성되는 것을 알 수 있다. 이를 이용하여 본 논문에서는 공간적인 분포 중에서 도 특징성이 강한 부분을 추출하기 위해 분포의 평균 에서 표준편차간의 확률을 구간 적분하여 특징정보 를 추출하였다.

표 1 은 각각의 객체에 대한 공간적 모델을 생성하 고 이동 궤적에 대한 확률분포를 추정하여 특징정보 를 추출하는 과정을 의사코드로 나타낸 것이다.

\section{2. 이동객체의 방향 서술자}

본 논문에서는 지역적이며 반복적인 움직임 정보 를 보이는 객체뿐만 아니라 불규칙적인 움직임을 보 이는 객체에 대해서도 배회행위를 검출하는 방법을 제안한다.

배회란 특정 목표 지점을 두고 보행하는 것이 아 니기 때문에 [정의 2]와 같이 예측할 수 없는 동선을 가지게 된다. 또한, 반복적인 움직임이 없는 배회패 턴이나 배회반경이 특정구역에 국한되어있지 않고 산발적인 움직임을 갖는 패턴에도 배회행위를 검출 하기 위해 본 논문에서는 이동 객체의 방향성[15]을 이용한다. 제안하는 방법은 먼저 표 2 와 같이 객체의 움직임 방향을 $45^{\circ}$ 씩 8 방향 $(\rightarrow \nearrow \uparrow \backslash \longleftarrow \backslash \downarrow)$ 으로 양자화 하여 $\mathrm{t}$ 프레임에서 객체의 방향성에 대한 대표 서술자[16]를 생성한다.
표 1. 궤적 확률분포 특징정보 추출에 대한 의사코드

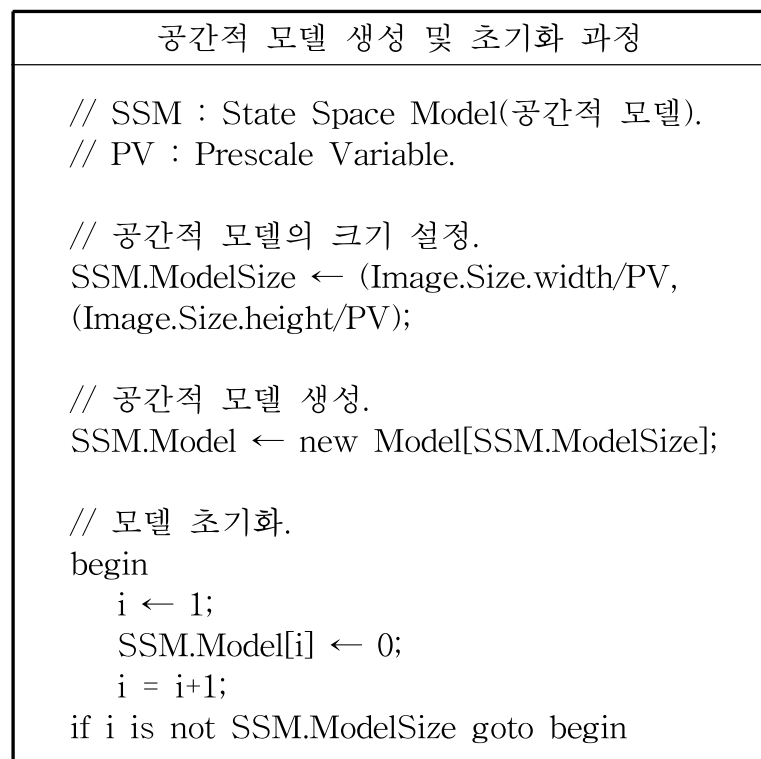

궤적 확률분포를 통한 특징정보 추출과정

begin

ObjectIndex $\leftarrow 1$;

Position $\leftarrow$ GetObjPosition(ObjectIndex);

begin'

$\mathrm{i} \leftarrow 1$;

if Position is not

Obj[ObjectInex].SSM.Model[i].region then $\mathrm{i}=\mathrm{i}+1$ continue;

end if

Obj[ObjectIndex].UpdateStateSpaceModel(i); exit;

if $i$ is not SSM.ModelSize goto begin'

(1) 공간적 모델 정규화.

Obj[ObjectIndex].NormalizationStateSpaceModel();

(2) 가우시안 필터를 통한 데이터 필터링.

Obj[ObjectIndex].GaussianFilterStateSpaceModel();

(3) 공간적 모델 갱신 및 벡터화. Obj[ObjectIndex].UpdateVector();

(4) 통계적 파라미터 추출 및 구간적분 추정 float Feature =

Obj[ObjectIndex].GetFeatureVector(Param);

if ObjectIndex is not NumOfObject goto begin

이 후 추출되는 객체의 이동방향에 따라 가중치를 부여하여 방향성에 대한 특징정보를 추출하였다. 보 행객체에 대한 방향변화를 파악하기 위하여 이전 프 
표 2. 이동객체의 움직임 양자화

\begin{tabular}{|c|c|c|c|c|c|c|c|c|}
\hline & 1 & (2) & (3) & (4) & (5) & (6) & (7) & (8) \\
\hline \hline 방향 범위 & $\begin{array}{c}339 \sim 390 \\
0 \sim 23\end{array}$ & $24 \sim 68$ & $69 \sim 113$ & $114 \sim 158$ & $159 \sim 203$ & $204 \sim 248$ & $249 \sim 293$ & $294 \sim 338$ \\
\hline 대표 서술자 & $\rightarrow$ & $\nearrow$ & $\uparrow$ & $\searrow$ & $\leftarrow$ & $\nearrow$ & $\downarrow$ & $\searrow$ \\
\hline
\end{tabular}

표 3. 방향성에 대한 상대적인 가중치

\begin{tabular}{|c|c|c|c|c|c|c|c|c|c|}
\hline & \multicolumn{9}{|c|}{ t-1 프레임 이동방향 } \\
\hline \multirow{9}{*}{$\begin{array}{l}\mathrm{t} \text { 프레임 } \\
\text { 이동방향 }\end{array}$} & & $\rightarrow$ & $\nearrow$ & $\overline{\imath \uparrow}$ & $\bar{\gamma}$ & $\leftarrow$ & 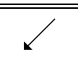 & $\downarrow$ & 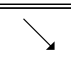 \\
\hline & $\rightarrow$ & 0.0 & 0.05 & 0.1 & 0.2 & 0.3 & 0.2 & 0.1 & 0.05 \\
\hline & $\nearrow$ & 0.05 & 0.0 & 0.05 & 0.1 & 0.2 & 0.3 & 0.2 & 0.1 \\
\hline & $\uparrow$ & 0.1 & 0.05 & 0.0 & 0.05 & 0.1 & 0.2 & 0.3 & 0.2 \\
\hline & $\nwarrow$ & 0.2 & 0.1 & 0.05 & 0.0 & 0.05 & 0.1 & 0.2 & 0.3 \\
\hline & $\leftarrow$ & 0.3 & 0.2 & 0.1 & 0.05 & 0.0 & 0.05 & 0.1 & 0.2 \\
\hline & $\swarrow$ & 0.2 & 0.3 & 0.2 & 0.1 & 0.05 & 0.0 & 0.05 & 0.1 \\
\hline & $\downarrow$ & 0.1 & 0.2 & 0.3 & 0.2 & 0.1 & 0.05 & 0.0 & 0.05 \\
\hline & $\searrow$ & 0.05 & 0.1 & 0.2 & 0.3 & 0.2 & 0.1 & 0.05 & 0.0 \\
\hline
\end{tabular}

레임의 방향성과 현재 프레임의 방향성을 비교하여 상대적인 가중치를 부여한다. 이는 방향의 변화가 많 이 발생하는 객체를 검출하기 위한 목적으로 방향 서술자는 각각의 대표방향에 대한 8 개의 상대적인 확률값을 가지게 된다. 표 3 은 방향성에 대한 가중치 를 나타낸 것이다. 시스템은 매 프레임마다 추출된 방향정보의 가중치를 각각의 대표방향에 누적하여 최종적으로 방향성에 대한 특징정보를 추출한다.

\section{4. 실험 및 결과 고찰}

본 논문에서 제안하는 배회행위검출 시스템은 인 텔코어 i5-2400 CPU 3.30GHz, GTX680, 메모리 4GB 의 하드웨어, MS Windows7 운영체제에서 Visual $\mathrm{C}++$ 을 이용하여 수행하였다. 다양한 이상행위를 검 출하기위해 자체 제작한 데이터와 PETS2007데이터 [17]를 이용하여 성능을 평가하였다. 자체 제작한 데 이터의 경우 실외에서 촬영한 데이터로 영상의 크기 가 640×480이며 PETS2007데이터의 경우 실내 환경 이며 $360 \times 288$ 영상이다.

본 논문에서 제안하는 배회행위검출 시스템은 객 체영역단위로 움직임 궤적을 추출하기 때문에 정확 한 객체영역단위의 궤적정보가 추출되지 않는다면
배회행위의 오검출 확률이 매우 높을 수밖에 없다. 이러한 문제점 해결을 위해 궤적을 보정하는 필터링 을 적용하여 이동 궤적의 노이즈를 제거할 수 있었 다.

그림 5(a)에 흰색으로 궤적을 나타낸 것을 보면 노이즈가 많은 것을 볼 수 있다. 움직이는 객체의 바 운딩 박스의 중심점을 이용하여 움직이는 객체의 위 치정보 및 방향을 특징으로 사용할 경우, 공간적 모 델의 확률분포가 부정확하기 때문에 정확한 행위파 악과 패턴을 인지할 수 없다. 그림 $5(\mathrm{~b})$ 는 특징정보추 출의 전처리 단계로 객체영역에 대해 칼만 필터 (kalman filter)[18]를 적용한 결과를 나타내며 그림 5(a)와 비교하였을 때 궤적의 노이즈가 제거되어 안 정화 되었다는 것을 볼 수 있다.

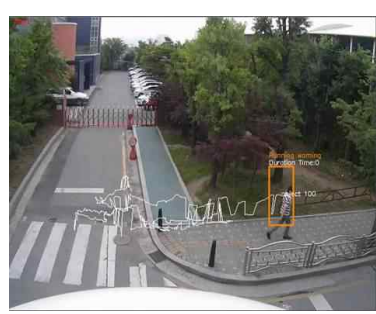

(a) 필터링 적용 전 궤적

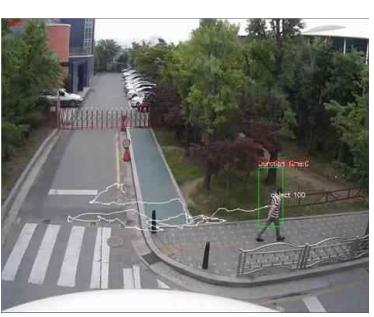

(b) 필터링 적용 후 궤적
그림 5. Filtering을 통한 이동객체의 영역 안정화 

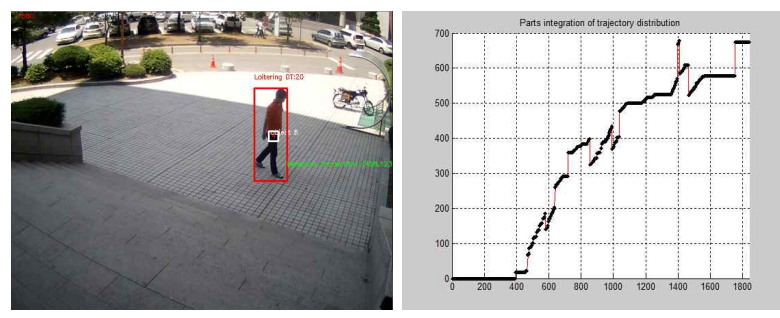

(a) S2_HBU_VIEW001 영상의 구간적분 데이
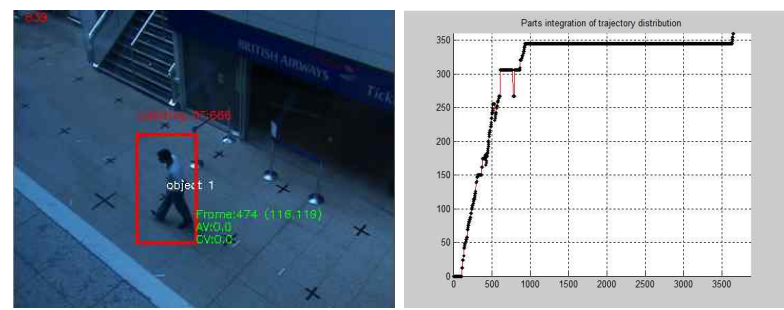

(b) PETS2007_S1 영상의 구간적분 데이터

그림 6. 배회행위 검출결과에 따른 구간적분 데이터 분석

그림 6 는 궤적 확률분포의 구간적분에 대한 데이 터를 분석한 것을 나타내었다. 각각의 실험데이터에 서 객체는 특정구역을 어슬렁거리며 배회하는 장면 을 담고 있으며, 그림 6(a)는 자체 제작한 데이터로 그림 6(b)의 PETS2007 데이터보다 배회반경이 넓고 반복적인 움직임이 활발하게 나타나도록 촬영하였 다. 그림 6의 그래프에서 시작프레임에서부터 상승 프레임까지 0 의 수치를 나타내고 있는데 이는 정상 보행객체로 분류되는 구간이다. 즉, 이동궤적에 대한 분포가 없기 때문에 그에 따른 구간적분 수치 또한
존재하지 않는 것이다. 정상적인 보행행위를 취하던 객체가 임의 구역에서 배회행위를 시작하게 되는 시 점을 그래프에서 상승구간으로 나타내었다. 배회 객 체가 특정구역에서 반복적인 움직임을 강하게 나타 내고, 배회반경이 좁을 경우 상승구간은 수직에 가까 우며, 반대로 배회반경이 넓고 동적 움직임이 적을 경우 상승구간은 서서히 증가한다. 그래프의 붉은 색 상 구간은 객체의 배회 구역이 변화하는 시점이다. 즉, 특정구역에서 반복적인 형태로 배회하던 객체가 구역을 옮겨 또 다른 임의의 구역에서 배회행위를 할 경우 나타나는 특징으로 그림 7 의 확률맵에서와 같이 반복적인 움직임이 강한 부분에서 높은 확률값 이 나타나기 때문에 객체의 움직임 변화에 따라 확률 분포도 변화하게 된다. 최종적인 확률분포는 특징성 이 더욱 강하게 나타나는 구간 근처에서 분포평균이 형성되고, 배회 반경에 따라 표준편차가 결정된다. 앞서 설명했듯이 자체 제작한 데이터는 PETS2007 벤치마크 데이터보다 배회반경이 넓기 때문에 그림 6(a)의 그래프와 같이 붉은 색상의 구간들이 많이 발 생하는 것을 확인할 수 있다. 반면에 PETS2007 데이 터는 좁은 배회반경과 객체 움직임이 동적에서 정적 으로 변화하여 상승구간은 급격히 증가하지만 구간 적분의 수치가 낮고 특정 구간부터 정체되어있는 것 을 알 수 있다.

그림 7은 실험데이터에 대한 객체의 이동궤적과 대표적인 방향변화를 나타낸 것이다. 궤적의 특성을

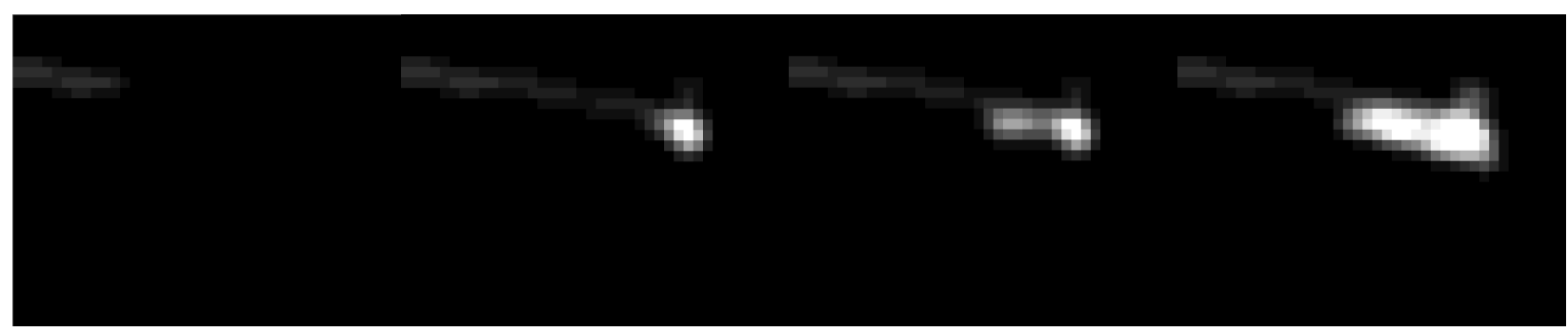

(a) S2_HBU_VIEW001 데이터
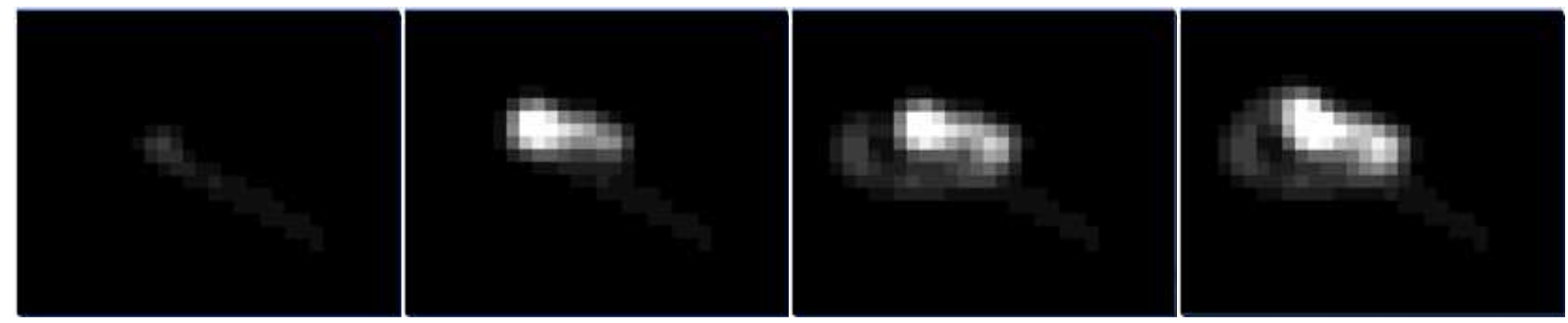

(b) PETS2007_S1 데이터

그림 7. 이동궤적에 대한 공간적 모델의 확률맵 
보면 알 수 있듯이 그림 8(a)의 PETS 2007 데이터는 많은 방향성을 띄고 있다. 본 논문에서는 인접프레임 간의 상대적인 방향정보에 대한 가중치를 부여하기 때문에 방향벡터의 분포가 클수록 높은 가중치를 부 여하게 된다. 따라서 그림 9 의 그래프와 같이 다른 데이터보다 PETS 2007 데이터가 방향특징정보 수 치가 높은 것을 알 수 있다. 그림 8(b), (c), (d)는 배회 궤적이 양방향 중심으로 이루어져 있기 때문에 반복 적인 움직임 특성이 강하고 반대로 방향특성은 약하
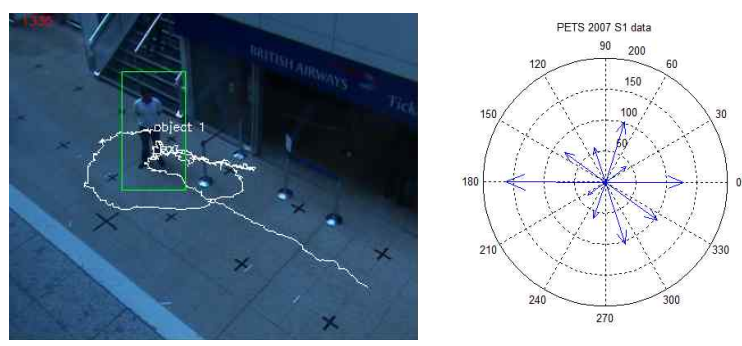

(a) PETS2007_S1 데이터
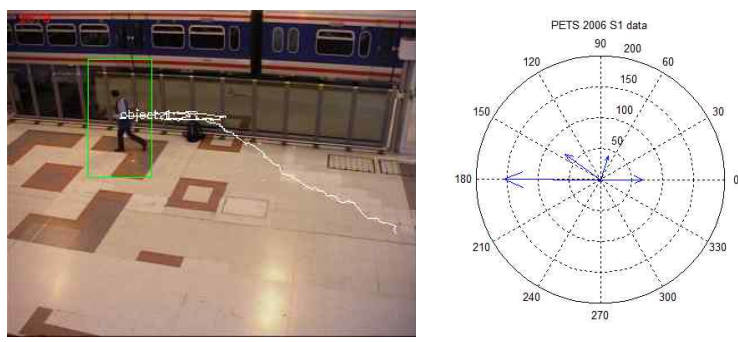

(b) PETS2006_S1 데이터
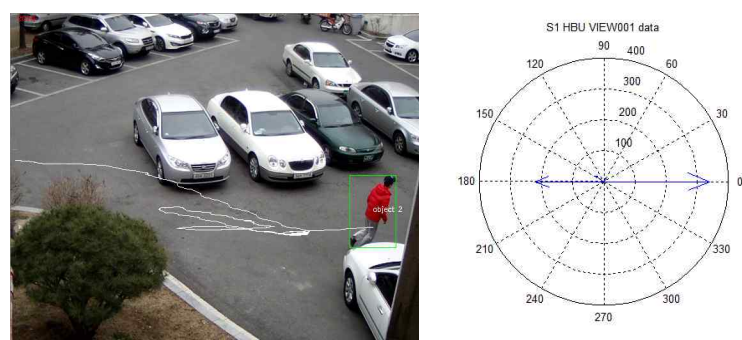

(c) S1_HBU_VIEW001 데이터
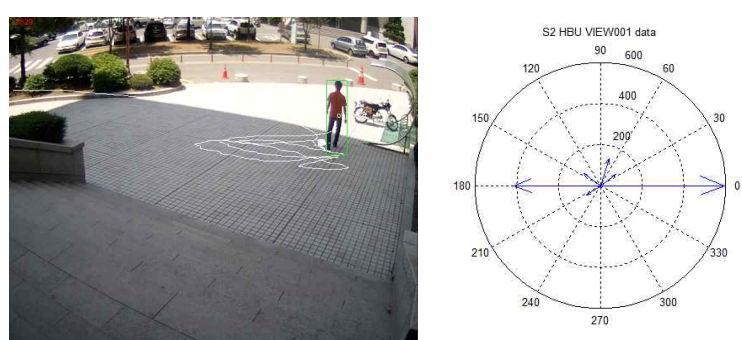

(d) S2_HBU_VIEW001 데이터

그림 8. 객체의 이동궤적과 방향변화

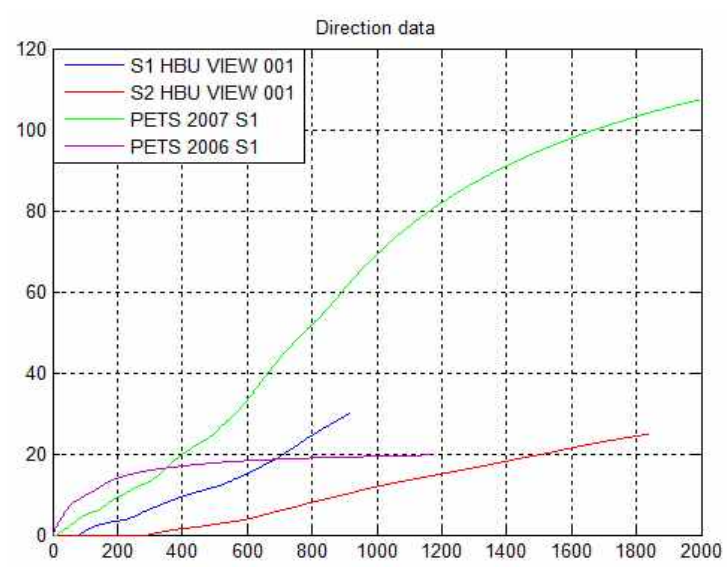

그림 9. 객체의 방향 특징정보

게 나타나게 된다.

본 논문에서는 배회행위에 대한 궤적을 분석하여 이동객체의 행위패턴과 특성을 파악하였다. 시간적 관점을 이용한 배회행위 검출기법과 공간적 관점을 이용한 배회행위 검출기법 보다 더욱 세밀한 객체의 행위패턴을 분석함으로써 배회행위의 시공간적인 결과를 얻어낼 수 있었다. 특히 궤적의 공간적 모델 과 방향서술자를 사용함으로써 다양한 배회행위에 서도 강인하게 검출할 수 있다는 사실을 확인하였다. 또한 공간적 모델은 이동궤적의 특징정보를 사전 확 률과 예측으로 묘사하여 시간적 흐름에 따라 공간적 인 객체의 행위패턴을 분석할 수 있었고, 배회행위에 대한 이동변화 흐름도 파악할 수 있었다. 방향 서술 자는 수시로 변화하는 움직임의 특성을 바탕함에 따 라 지역적인 움직임의 한계를 극복할 수 있었다. 그 림 10은 궤적정보와 방향정보를 통한 배회행위 검출 기법의 결과를 나타내고 있다.

\section{5. 결 론}

본 논문에서는 지능형 감시 시스템 분야에 적용할 수 있는 다양한 패턴의 배회행위를 검출하는 방법을 제안하였다. 기존의 많은 시스템에서는 특정 영역을 오랫동안 머무르는 행위를 배회라고 정의하여 영상 의 영역을 블록 단위로 나누어 검출하는 방법을 많이 사용하였다. 하지만 이러한 방법의 경우 장시간 넓은 지역을 어슬렁거리는 배회행위는 검출할 수 없다. 본 논문에서는 감시 시스템에 적합한 다양한 배회행위 를 검출하기 위해 새롭게 정의를 내렸고, 이를 토대 로 이동객체의 궤적을 분석하여 시공간적인 움직임 


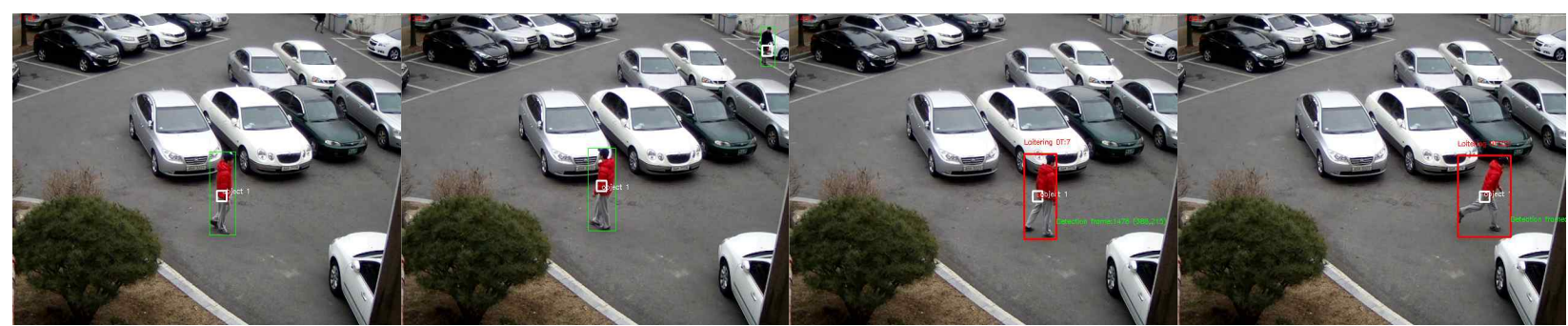

(a) S1_HBU_VIEW001 데이터

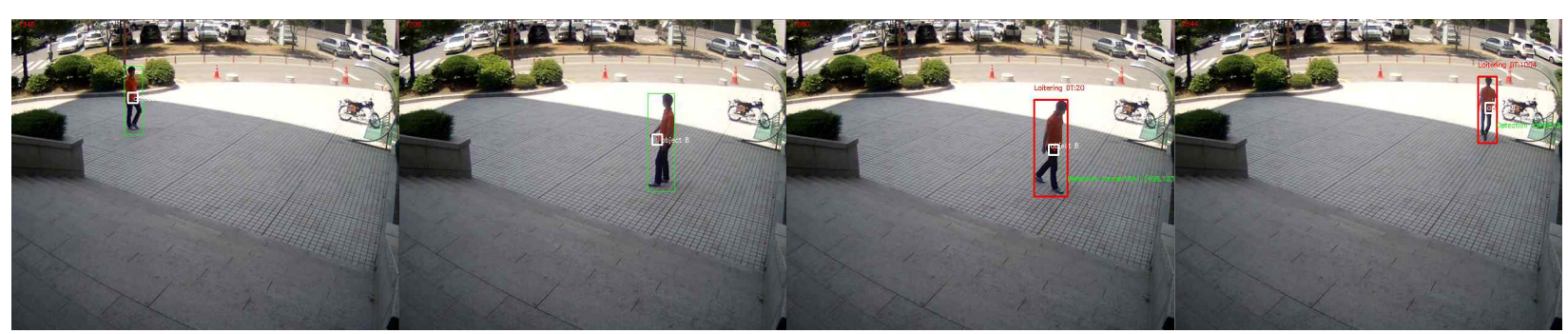

(b) S2_HBU_VIEW001 데이터

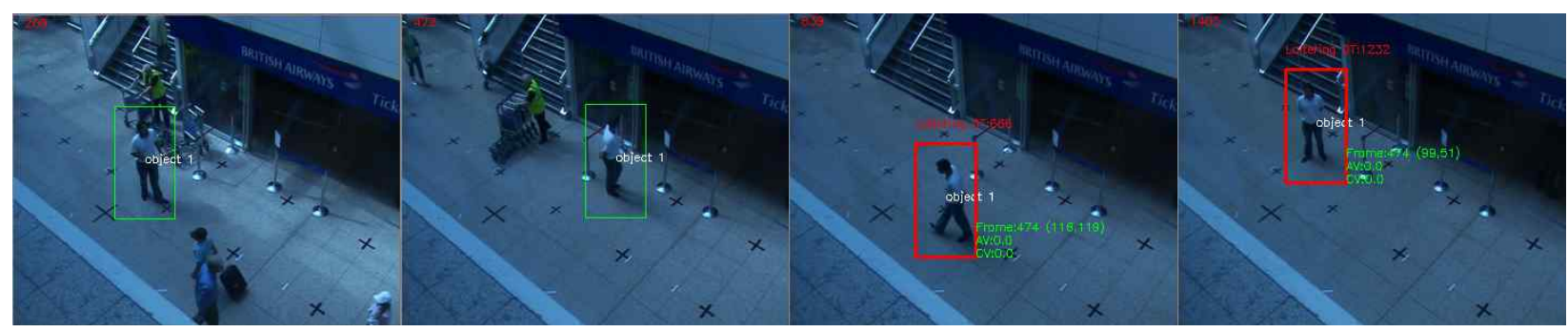

(c) PETS2007_S1 데이터

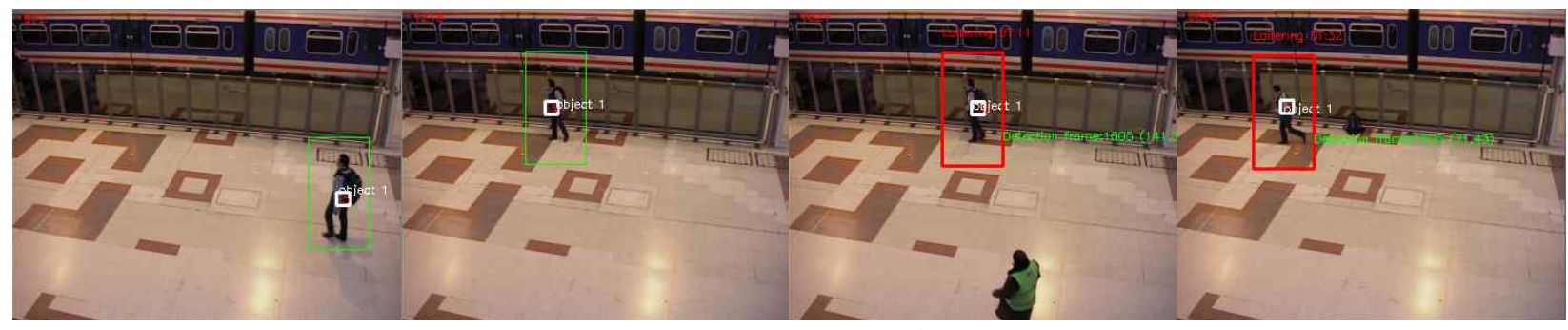

(d) PETS2006_S1 데이터

그림 10. 궤적정보와 방향정보를 통한 배회행위 검출결과(빨간색 영역 정보가 배회행위로 검출된 결과)

패턴을 분석할 수 있었다. 다양한 배회행위 검출의 성능평가를 위해 자체 제작한 실험 데이터와 공개된 데이터를 사용하였으며 실시간 배회행위 검출이 가 능함을 보였다. 그러나 추적기반의 객체 영역에 대한 의존도가 높아 정상적인 객체검출 및 추적이 이루어 지지 않을 경우 정확한 결과를 얻지 못하는 한계점을 발견하였다. 이에 대한 문제 해결방안을 향후 연구방 향으로 선정하고 다수 군중무리에서 이상행위 발생 여부를 판단할 수 있는 시스템으로 확장하고자 한다.
참 고 문 헌

[1] 정치윤, 한종욱, “지능형 영상분석 이벤트 탐지 기술동향," 전자통신동향분석, 제 27 권, 제4호, pp. 114-122, 2012.

[2] 이승원, 김태경, 유장희, 백준기, “지능형 비디오 분석을 위한 적응적 배경 생성 기반의 이상 행 위 검출," 대한전자공학회논문지, 제 48 권, 제 1 호, pp. 111-121, 2011.

[3] Chung-Hsien Huang, Ming-Yu Shih, Yi-Ta 
$\mathrm{Wu}$ and Jau-Hong Kao, "Loitering Detection Using Bayesian Appearance Tracker and List of Visitors," Advances in Multimedia Information Processing, PCM'08, LNCS 5353, pp. 906-910, 2008.

[4] Thi Thi Zin, Pyke Tin, and Takashi Toriu, "A Markov Random Walk Model for Loitering People Detection," International Conference on Intelligent Information Hiding and Multimedia Signal Processing, pp. 680-683, 2010.

[5] 박은수, 김학일, "그림자 제가와 색도 히스토그 램 비교를 이용한 배회행위검출," 한국정보보호 학회논문지, 제21권, 제6호, pp. 159-169, 2011.

[6] Nathaiel D. Bird, Osama Masoud, Nikolaos P. Papanikolopoulos, and Aaron Isaac, "Detection of Loitering Individuals in Public Transportation Areas," IEEE Transactions on Intelligent Transportation Systems, Vol. 6, No. 2, pp. 167-177, 2005.

[7] Mohannad Elhamod and Martin D. Levine, "Automated Real-Time Detection of Potentially Suspicious Behavior in Public Transport Areas," IEEE Transactions on Intelligent Transportation Systems, Vol. 14, No. 2, pp. 688-699, 2013.

[8] Aergio A. Velastin, Boghossian A. Boghossian, Benny Ping Lai Lo, Jie Sun, and Maria Alicia Vicencio-Silva, "PRISMATICA: Toward Ambient Intelligence in Public Transport Environments," IEEE Systems. Man. and Cybernetics, Vol. 35, No. 1, pp. 164-182, 2005.

[9] A. Singh, S. Sawan, M. Hanmandlu, V.K Madasu, and B.C. Lovell, "An Abandoned Object Detection System Based on Dual Background Segmentation," Proc. Int. Conf. Advanced Video, Signal Based Surveillance, pp. 352-357, 2009.

[10] G.G. Lee, J.J. Kim, and W.Y. Kim, "A Fast Background Subtraction Method Robust to High Traffic and Rapid Illumination Changes,"
Journal of Korea Multimedia Society, Vol. 13, No. 3, pp. 417-429, 2010.

[11] Arnold Wiliem, Vamsi Madasu, Wageeh Boles, and Prasad Yarlagadda, "Detecting Uncommon Trajectories," Digital Image Computing. Techniques and Applications, pp. 398-404, 2008.

[12] Hua Yang, Yihua Cao, Shuang Wu, and Weiyao Lin, "Abnormal Crowd Behavior Detection Based on Local Pressure Model," Signal and Imformation Processing Association Annual Summit and Conference, pp. 1-4, 2012.

[13] Myo Thida, How-Lung Eng, and Paolo Remagnino, "Laplacian Eigenmap with Temporal Constraints for Local Abnormality Detection in Crowded Scenes," IEEE Transactions on Cybernetics, Vol 43, No. 6, pp. 1-10, 2013.

[14] Sunil Kumar Kopparapu and M Satish, "Identifying Optimal Gaussian Filter for Gaussian Noise Removal," 2011 Third National Conference on Image Processing and Graphics, pp. 126-129, 2011.

[15] Tian Wang and Hichem Snoussi, "Histograms of Optical Flow Orientation for Visual Abnormal Events Detection," 2012 IEEE Ninth International Conference on Advanced Video and Signal-Based Surveillance, pp. 13-18, 2012.

[16] G.T. Bea, S.Y. Kwak, and H.R. Byun, "Abnormal motion detection using dominant motion analysis," Workshop on Image Processing and Image Under-Standing, 2010.

[17] PETS 2007 Benchmark data, http://www.hitech-projects.com/euprojects/ cantata/datasets_cantata/dataset.html, 2007.

[18] D. Simon, "Kalman Filtering with State Constraints: A Survey of Linear and Nonlinear Algorithms," Control Theory and Applications. IET, Vol. 4, No. 8, pp. 13031318, 2010. 


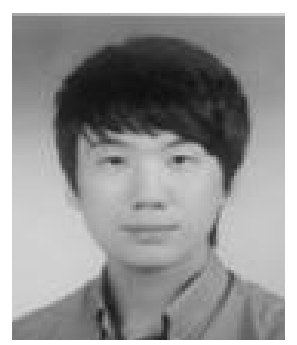

강 주 형

2004년 3월 2012년 2월 국립한 밭대학교 제어계측공학 과 학사

2012년 2월 현재 국립한밭대학 교 제어계측공학과 석사 과정

관심분야: 영상처리, 컴퓨터 비전, 지능형감시

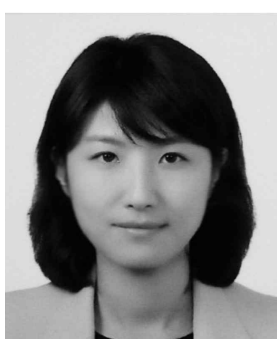

곽 수 영

2010년 2월 연세대학교 컴퓨터과 학과 공학박사

2010년 3월 2011년 1월 삼성전 자 영상디스플레이사업부 책임연구원

2011년 2월 현재 국립한밭대학 교 전자·제어공학과 조 교수

관심분야: 영상처리, 컴퓨터비전, 지능형시스템 